\title{
The allometry of the arcuate body in the postembryonic development of the giant house spider Eratigena atrica
}

\author{
Teresa Napiórkowska ${ }^{1}$ D . Jarosław Kobak ${ }^{1}$
}

Received: 11 October 2017 / Accepted: 23 February 2018 / Published online: 10 March 2018

(c) The Author(s) 2018. This article is an open access publication

\begin{abstract}
The brain of arachnids contains a special neuropil area called the arcuate body (AB), whose function has been widely discussed. Its growth and proportion in the brain volume during postembryogenesis have been investigated only in several spider species. Our allometric study is aimed at determining to what extent the development of the AB in Eratigena atrica, a spider with unique biology and behaviour, is similar to the development of this body in other species. We put forward a hypothesis of allometric growth of this body in relation to the volume of the central nervous system (CNS) and its neuropil as well as in relation to the volume of the brain and its neuropil. The analysis of paraffin embedded, $H+E$ stained histological preparations confirmed our hypothesis. The AB developed more slowly than the CNS and the neuropil of both the brain and the CNS. In contrast, it exhibited positive allometry in relation to the volume of the brain. This body increased more than nine times within the postembryonic development. Its proportion in the brain volume varied; the lowest was recorded in larvae and nymphs I; then, it increased in nymphs VI and decreased to $2.93 \%$ in nymphs X. We conclude that in Eratigena atrica, the $\mathrm{AB}$ develops differently that in orb-weaver and wandering spiders. There is no universal model of the $\mathrm{AB}$ development, although in adult spiders, regardless of their behaviour, the proportion of this area in the brain volume is similar.
\end{abstract}

Keywords Allometry $\cdot$ Arcuate body $\cdot$ Central nervous system $\cdot$ Postembryonic development $\cdot$ Spider

\section{Introduction}

The arthropod brain contains neuropil areas having special functions. For example, in insects, they may be responsible for walking (Strauss 2002), sounds (Hoffmann et al. 2007), long-term olfactory memory (Wu et al. 2007) and polarized vision (Heinze and Homberg 2007). Such areas also occur in Chelicerata. One of them, located in the back of the protocerebrum, is known as the arcuate body (AB) (Strausfeld et al. 1993, 2006; Strausfeld 1998; Homberg 2008) and previously also as the central body (e.g. Babu 1965; Satija et al. 1970a, 1980; Babu and Barth 1984; Wegerhoff and Beridbach 1995). The later term is still in use (Foelix 1996; Barth 2002; Hwang and Moon 2003; Park and Moon 2013; Park et al. 2013), though, due to the lack of the homology of this structure with the "central complex" structures of insects

Teresa Napiórkowska

tnapiork@umk.pl

1 Department of Invertebrate Zoology, Faculty of Biology and Environmental Protection, Nicolaus Copernicus University, Lwowska 1, 87-100 Toruń, Poland
(Homberg 1987; Hanesch et al. 1989; Strausfeld 1999) and malacostracans (Utting et al. 2000; Loesel et al. 2002), the term "arcuate body" seems to be more suitable (Strausfeld et al. 1993, 2006; Strausfeld 1998; Homberg 2008).

$\mathrm{AB}$ has been shown in many chelicerates: Pycnogonidae, Xiphosurida, Scorpionida, Solifugae, Thelyphonida, Opilionida and Araneida (Babu 1965; Loesel et al. 2002; Harzsch et al. 2005; Loesel et al. 2011). It is vestigial or absent only in Acari (Ioffe 1963). This unpaired, crescent-shaped neuropil mass is located in the back region of the brain. It is not built into the protocerebrum, but occupies the dorsal surface, lying transversely to the long body axis (Fig. 1). The crescent horns point forward (Satija et al. 1970a, b; Satija et al. 1980; Babu and Barth 1984; Wegerhoff and Beridbach 1995; Barth 2002; Kovoor et al. 2005; Loesel et al. 2011; Park et al. 2013). AB is composed of lobes. In spiders, there are two lobes of similar thickness: anterodorsal and posteroventral (Babu and Barth 1984; Barth 2002; Doeffinger et al. 2010; Park et al. 2013), although Babu (1965) distinguished three lobes in Poecilotheria: anterior, central and posterior (situated ventrally to the others). In Lycosa tarentula, these two lobes are not set in the same horizontal plane: $2 / 3$ of 


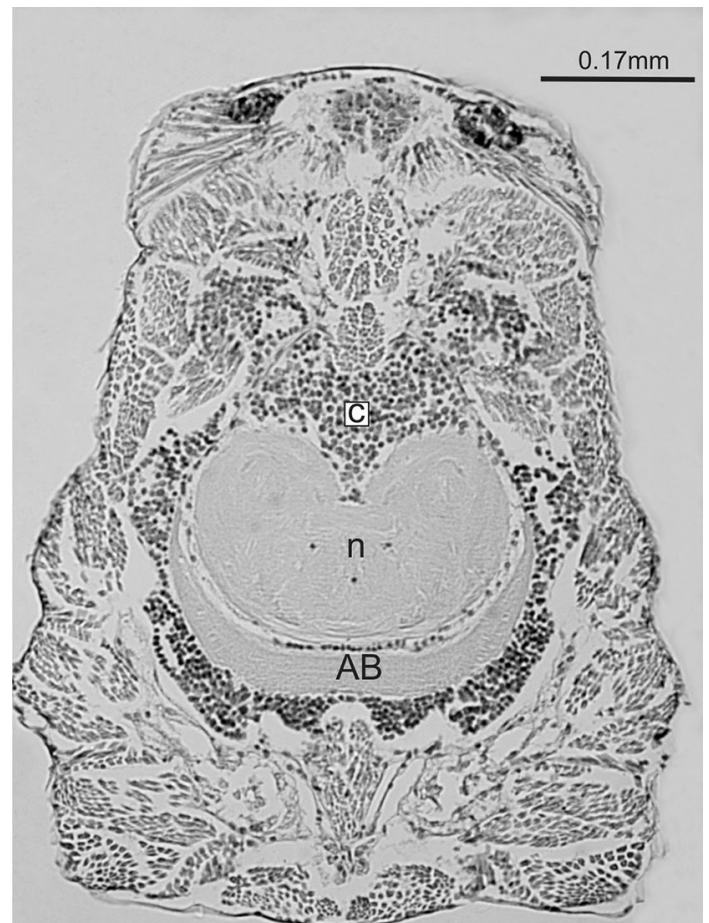

Fig. 1 Horizontal section through the prosoma and brain of Eratigena atrica nymph II; $A B$ arcuate body, $c$ cortex, $n$ neuropil

the inner surface of the posteroventral lobe is covered by the anterodorsal one (Kovoor et al. 2005). Each lobe has a layered structure. Five layers were distinguished in Lycosa tarentula by Kovoor et al. (2005) in the anterior lobe, and only two in the posterior one. Their texture results from branched fibres oriented in different directions, and from the accumulation of numerous synaptic connections. The $50-\mu \mathrm{m}$-thick brain cortex covers the entire surface of the anterodorsal lobe and only $50 \%$ of the posteroventral one. The AB cortex contains several neuron types. Their projections form a multi-column, palisade-like organization of the AB.

The function of the arachnid $\mathrm{AB}$ has long been discussed. It has been suggested to play a role in the web building, as lesions in the cortex close to the $\mathrm{AB}$ led to abnormalities in the web structure of web-weaving spiders (Witt 1969) and the beginning of web production in Argiope aurantia coincided with the formation of AB (Babu 1975). However, the hypothesis that the $\mathrm{AB}$ is best developed in web-weaving spiders has not been confirmed. Weltzien and Barth (1991) have revised the view that the $\mathrm{AB}$ is the main centre of web spinning. They compared the volume of different brain regions, including $A B$, in four spiders with different behaviour. The proportion of the $\mathrm{AB}$ volume in the brain volume was always similar and relatively small, ranging from 3.1 to $5.1 \%$. Thus, the $\mathrm{AB}$ does not only coordinate web weaving, especially as it has also been found in non-weaving arachnids, for example, scorpions (Babu 1965). Strausfeld et al. (1993) showed the association of the AB with the optical system of spiders and other arachnids. In spiders, the optical pathway leading from the principal antero-median eyes does not end in the first optical neuropil, running further to two other neuropil masses, one of them being the $\mathrm{AB}$ (Foelix 1996).

Numerous studies of the central nervous system (CNS) of spiders have focused on the $\mathrm{AB}$ presence and structure (e.g. Babu 1965, 1969, 1975; Babu and Barth 1984; Wegerhoff and Beridbach 1995; Park and Moon 2013), but have largely ignored its morphometry. This omission may have resulted from the fact that for many years, the AB function has not been fully understood. Weltzien and Barth (1991) performed a morphometric analysis of the brain and its centres in four juvenile and/or adult spiders from different families: $C$. salei, $N$. clavipes, $P$. regius and Ephebopus sp. Satija et al. $(1969,1970 \mathrm{a}, \mathrm{b})$ evaluated the volume of the AB in ecribellate (Crossopriza lyoni and Cyrtophora citricola) and cribellate spiders (Stegodyphus pacificus, Oecobius putus, Filistata poonaensis). In C. lyoni, C. citricola and S. pacificus, the $\mathrm{AB}$ proportion in the brain volume was $5-7 \%$, and in $O$. putus and $F$. poonaensis, $35 \%$. The latter result differs considerably from the results obtained by Weltzien and Barth (1991) and by Satija et al. (1969, 1970b) and is not fully credible. However, it cannot be excluded that in some spiders, the $\mathrm{AB}$ occupies a greater part of the brain than in the species examined so far.

To shed new light on the issue, we conducted a morphometric study of the $\mathrm{AB}$ in Eratigena atrica (Agelenidae). In Agelenidae, the $\mathrm{AB}$ volume and proportion in the brain volume have not been determined yet. We assumed that our results might be different from those obtained by Weltzien and Barth (1991) and Satija et al. (1969, 1970a, b) due to the unique behaviour of this species. E. atrica builds specific flat webs with a funnel at one end, where the spider lurks. The web structure is simple and does not require great precision, leg coordination or spatial orientation, i.e. features found in typical web-weaving spiders. Moreover, E. atrica often leaves their webs to hunt. Thus, it may be viewed as intermediate between web-weaving and wandering spiders. We put forward a hypothesis of an allometric growth of this body in relation to the volume of the entire central nervous system and its neuropil as well as to the volume of the brain and its neuropil. We assumed that, if the $\mathrm{AB}$ is responsible for a particular behaviour type, such as web weaving or locomotion, there will be an association between the life style of particular spider species and the relative size and/or allometric growth of their AB. Eratigena atrica, occupying an intermediate position between typical web-weaving and wandering species, should exhibit intermediate parameters of the $\mathrm{AB}$ growth. Also, the role of the $\mathrm{AB}$ in walking would result in the increase in the importance of this structure 
when developing individuals start to move actively. Therefore, we compared our results with those obtained for spiders differing in behaviour type by Babu (1975) and Weltzien and Barth (1991).

\section{Materials and methods}

The study involved Eratigena atrica C. L. Koch (Agelenidae) from our laboratory culture, established at the end of August 2014. Sexually mature spiders (34 females, 18 males) were collected in the vicinity of Torun and Chełmża (Poland) and transferred to a dark laboratory room with temperature of $21-23{ }^{\circ} \mathrm{C}$ and relative humidity of $70 \%$. Each individual was placed in a 500-ml glass jar which contained water-soaked cotton ball and fed twice a week with larvae of Tenebrio molitor. Several weeks later, sexually mature males were introduced into the jars with females. The procedure was repeated twice, each time with a different male. Females laid first cocoons 3-4 weeks after the last copulation. The cocoons were cut open to remove eggs, subsequently incubated in conditions optimum for embryonic development of this spider species, i.e. at the temperature of $21-23{ }^{\circ} \mathrm{C}$ and relative humidity of $70 \%$ (Jacuński et al. 1994; Jacuński and Wiśniewski 1997). In the next step, we randomly selected 15 larvae (called postembryos) (Downes 1987; Wolff and Hilbrant 2011) from a large population and fixed them on the second day after hatching. The remaining larvae were further cultured. Subsequent stages were kept in separate jars and fed twice a week: juveniles with newly laid eggs of E. atrica, while later stages, with larvae of Tribolium sp. and Tenebrio molitor. The spiders were monitored every day to capture molts, which indicated their transition to the next developmental stage. All spiders were fixed on the second day after casting off the exuvium. In total, we fixed 165 individuals, 15 of each developmental stage (from larvae to nymphs X). At this point, we decided to close the culture because we already have one male among the 15 specimens. We assumed that the remaining 14 individuals were females, which needed one more molt to reach sexual maturity. Eventually, though, only females were subjected to the morphometric analysis.

Spiders were fixed with Bouin solution, composed of saturated picric acid, formalin and acetic acid (15, 5 and $1 \mathrm{ml}$, respectively). The fixation time was $72 \mathrm{~h}$, but after $48 \mathrm{~h}$, when the tissues were initially fixed, spiders had all appendages removed. Older stages also had their opisthosoma removed for better penetration of the tissues with the fixative.

The fixed tissues were washed in ethanol of increasing alcohol content (from 70 to $100 \%$ ) for dehydration. The dehydrated material was passed through a mixture of absolute alcohol and xylene (1:1), then twice through pure xylene. Next, it was transferred to a mixture of xylene and paraffin (1:1) and finally to pure paraffin. The paraffin blocks were cut into $7 \mu \mathrm{m}$ horizontal sections using HM $355 \mathrm{~S}$ Microm rotary microtome. The sections were placed on slides, dried, stained with Mayer hematoxylin and eosin and embedded in euparal.

Morphometric analysis was performed on ten specimens of each developmental stage, for which we obtained a complete series of stained sections. Each section was photographed under a microscope with a digital camera connected to the computer. ImageJ software (freeware by W. S. Rasband, US National Institutes of Health, Bethesda, Maryland, USA, https://imagej.nih.gov/ij/) was used to determine the surface of the central nervous system (consisting of the brain and subesophageal ganglion) (hereafter referred to as the CNS) in each slide (Fig. 2a, b). If a series was incomplete (ca. $2 \%$ of sections were missing), we averaged the measurements of the previous and next sections. The procedure was similar for determining the surface of the brain (cortex and neuropil). The position of the oesophagus visible on the sections was considered a criterion for distinguishing the brain (including ganglia of chelicerae) from the subesophageal ganglion. We also determined the surface of the neuropil of the CNS (the brain and subesophageal ganglion), of the brain and of the arcuate body. We multiplied the surfaces $\left(\right.$ in $\mathrm{mm}^{2}$ ) by their thickness to obtain the total volume of all elements (in $\mathrm{mm}^{3}$ ). Subsequently, the measurements were used to determine the following: 1/proportion of the brain volume in the CNS volume, 2/proportion of the brain neuropil volume in the brain volume, 3/proportion of the $\mathrm{AB}$ volume in the CNS neuropil volume, 4/proportion of the $\mathrm{AB}$ volume in the brain volume and 5/proportion of the $\mathrm{AB}$ volume in the brain neuropil volume.

To find allometric relationships between the volumes of the particular parts of the CNS, the reduced major axis regression (RMA) was applied to the log-transformed data (with all the developmental stages included). The slope of such a regression line is equivalent to the exponent $(b)$ of the allometric equation $y=a x^{b}$. The exponents of the allometric equations (allometric growth coefficients $b$ ) were compared with the theoretical value of 1 , corresponding to the isometric growth. The significance tests of the departure of $b$ coefficients from 1 were based on the test statistic according to McArdle (1987):

$T=\frac{\left|\log b-\log \beta^{\prime}\right|}{\left(\left(1-r^{2}\right)(n-2)\right)^{1 / 2}}$ with $d f=2+\left((n-2) /\left(1+0.5 r^{2}\right)\right)$

where $b$ - the allometric growth coefficient (RMA regression slope), $\beta^{\prime}-$ the isometric value of the coefficient (here: 1), $r$-the Pearson correlation coefficient and $n$-the number of data points. 

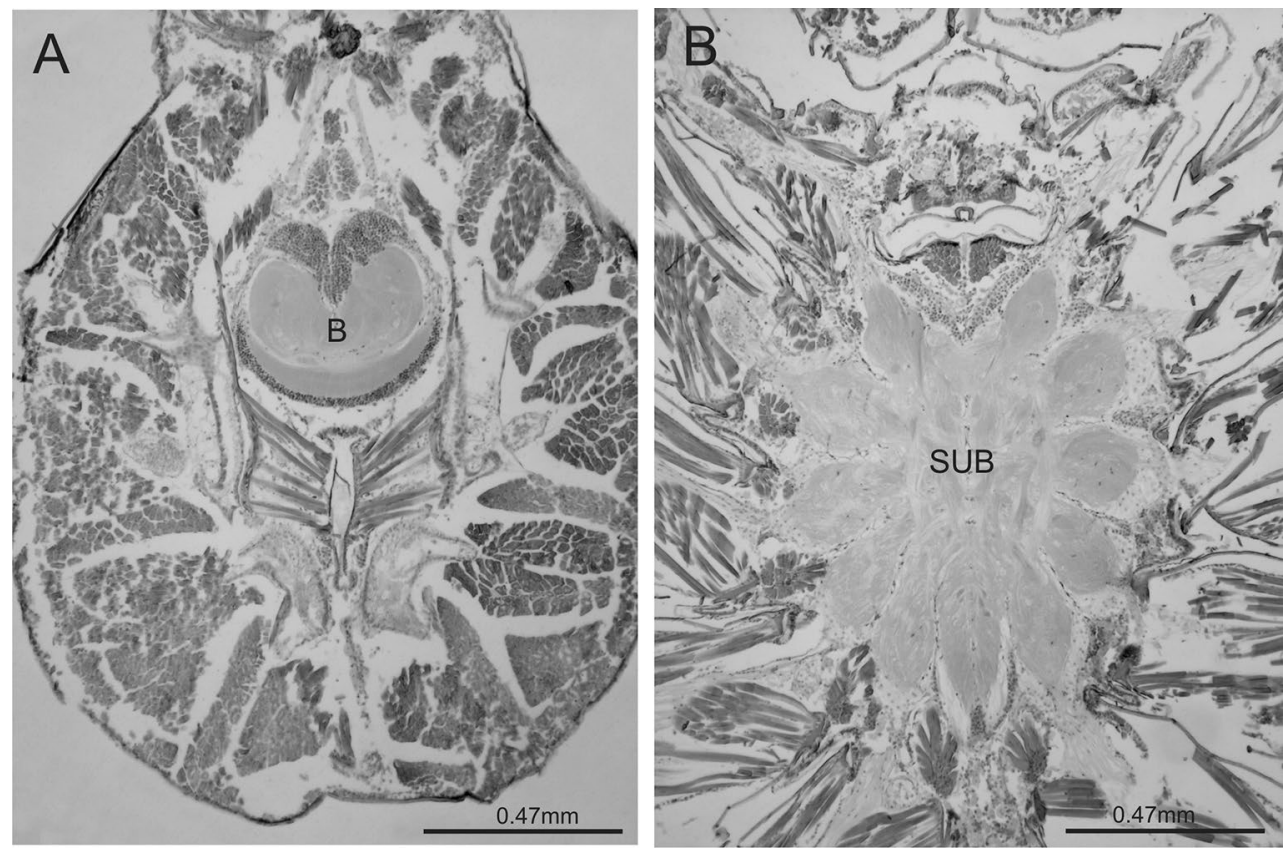

Fig. 2 Horizontal sections through the prosoma, brain (a) and subesophageal ganglion (b) of Eratigena atrica nymph VI; $B$ brain, SUB subesophageal ganglion

Exponents different from 1 indicate a positive $(b>1)$ or negative $(b<1)$ allometric growth. We checked the relationships between the volume of the arcuate body and the volume of: (1) the total CNS (2) the CNS neuropil, (3) the brain and (4) the brain neuropil.

\section{Results}

In E. atrica cultured in laboratory inter-molt periods varied in length. Larvae molted 5-6 days from hatching, whereas nymph stages lasted from 12 (nymph I) to 55 days (nymph IX) on average. Nymphs I and next stages were active, built webs and fed on provided food. Each molt was accompanied by an increase in the volume of the CNS and its components (Table 1).

From the larval to nymph X stage, the volume of the CNS increased approximately 19 times and that of its neuropil approximately 39 times. The volume of the brain increased approximately six times: in larvae, it constituted nearly $50 \%$ of the volume of the CNS, whereas in nymphs X, only about $15 \%$. The proportion of the brain neuropil in the brain volume increased with each molt, constituting over $60 \%$ in nymphs $\mathrm{X}$.

The $\mathrm{AB}$ in E. atrica was clearly visible in all developmental stages (Fig. 1) and grew within the entire postembryonic development. Interestingly though, it had the same volume in larvae and nymphs I (Table 1, Fig. 3). Its increase was recorded only in nymphs II and later stages. In total, the arcuate body increased its volume more than nine times. Nevertheless, this area developed more slowly than the entire central nervous system and its neuropil, as indicated by the negative results of allometric tests (Table 2, Fig. 3a, b). Because of the intense growth of the CNS neuropil, the proportion of this body in the CNS neuropil volume decreased more than four times. However, positive results of allometric tests indicate that the $\mathrm{AB}$ developed faster than the brain (Table 2, Fig. 3c). It constituted $1.84 \%$ of the brain in nymphs I and $4.36 \%$ in nymphs VII (Table 1). On the other hand, the volume of the $\mathrm{AB}$ was negatively allometrically related to the volume of the brain neuropil (Table 2, Fig. 3d), indicating that this body developed much more slowly than the other neuropil areas in the brain. The proportion of the $\mathrm{AB}$ in the brain neuropil volume varied, ranging from $4.69 \%$ in nymphs IX to $7.29 \%$ in nymphs III (Table 1).

\section{Discussion}

Our study confirms the hypothesis of allometric growth of the arcuate body in subsequent stages of Eratigena atrica. The results indicate that the arcuate body increased ten times within the postembryonic development. Interestingly, however, in two initial developmental stages, the volume of body did not increase. It was only in nymphs II that it grew rapidly, doubling in size and marking the biggest increase in relation to the previous stage. It can thus be concluded that there is a relationship between spiders leaving the cocoon 


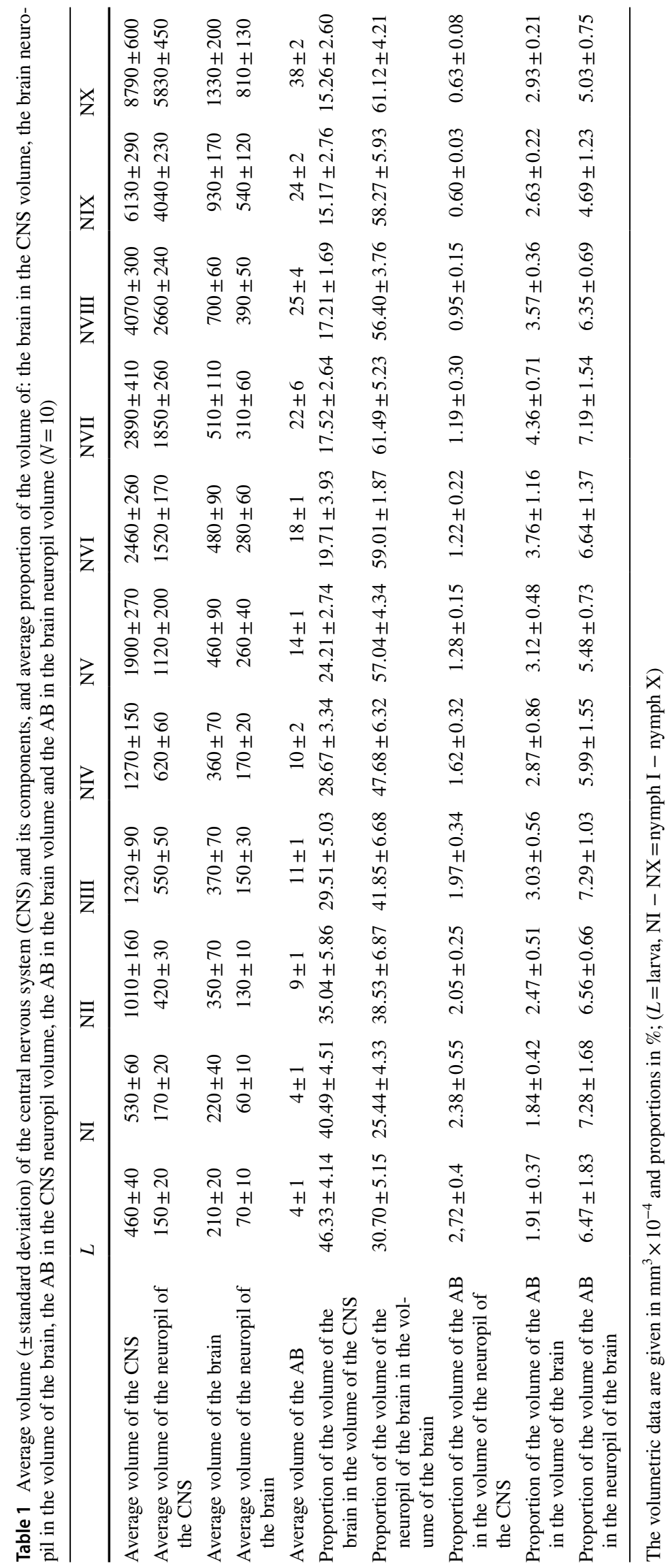


Fig. 3 Relationship between the volume of the arcuate body and the volume of: a the total central nervous system, $\mathbf{b}$ total neuropil, $\mathbf{c}$ brain and $\mathbf{d}$ brain neuropil during the postembryonic development of Eratigena atrica. Ten individuals of each developmental stage were measured
Table 2 Allometric relationships (reduced major axis regression, RMA) between the volume of the arcuate body $(\mathrm{AB})$ and the volumes of various structures $(X)$ of the central nervous system (CNS) of Eratigena atrica
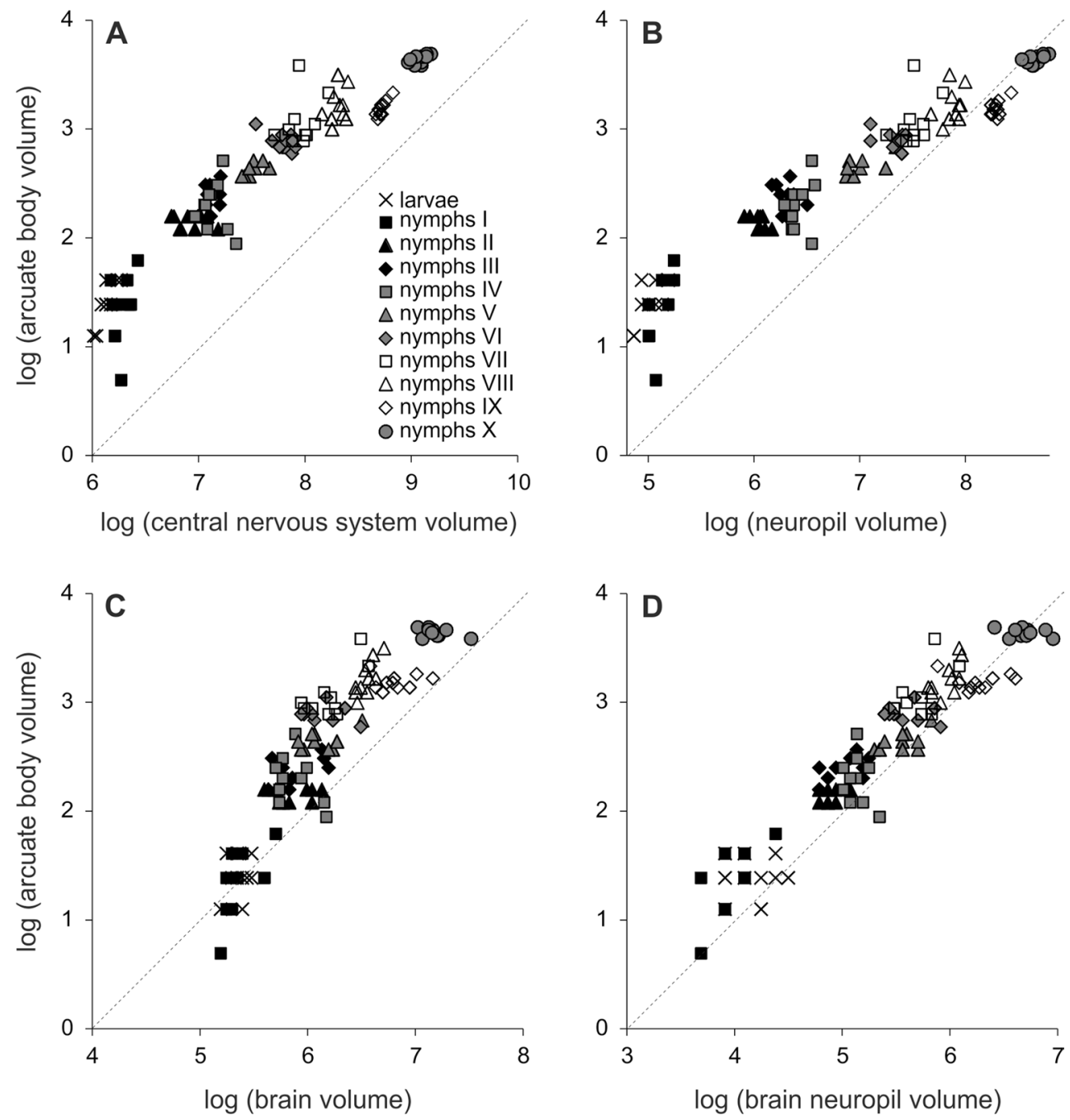

\begin{tabular}{|c|c|c|c|c|c|c|c|}
\hline \multirow[t]{2}{*}{ CNS part $(X)$} & \multicolumn{3}{|c|}{$\begin{array}{l}\text { Pearson correlation coef- } \\
\text { ficient }\end{array}$} & \multicolumn{2}{|c|}{$\begin{array}{l}\text { Parameters of the RMA: log } \\
(\mathrm{AB})=B \log (X)+A\end{array}$} & \multicolumn{2}{|c|}{$\begin{array}{l}\text { Isometry test: } H 0 \text { : } \\
B=1\end{array}$} \\
\hline & $r$ & $t_{108}$ & $P$ & $B \pm \mathrm{SE}$ & $A \pm \mathrm{SE}$ & $t_{110}$ & $P$ \\
\hline Total CNS & 0.954 & 33.06 & $<0.001$ & $0.798 \pm 0.023$ & $-3.456 \pm 0.175$ & 7.83 & $<0.001$ \\
\hline Total neuropil & 0.967 & 39.38 & $<0.001$ & $0.623 \pm 0.015$ & $-1.718 \pm 0.107$ & 19.28 & $<0.001$ \\
\hline Brain & 0.906 & 22.23 & $<0.001$ & $1.294 \pm 0.053$ & $-5.366 \pm 0.324$ & 6.33 & $<0.001$ \\
\hline Brain neuropil & 0.957 & 34.18 & $<0.001$ & $0.890 \pm 0.025$ & $-2.214 \pm 0.135$ & 4.15 & 0.001 \\
\hline
\end{tabular}

The isometry test shows whether the slope of the RMA line $(b)$ significantly departs from 1, i.e. whether the $\mathrm{AB}$ grows slower $(B<1)$ or faster $(B>1)$ than the given part of the CNS and starting an active lifestyle and the enlargement of the $\mathrm{AB}$, which suggests its coordinating and associative functions. This is also confirmed by the connection of the $\mathrm{AB}$ to the subesophageal ganglion through motor fibres (e.g. a large protocerebro-dorsal tract) (Babu and Barth 1984; Foelix 1996; Barth 2002; Park et al. 2013).

Weltzien and Barth (1991) described the development of the $A B$ in the postembryogenesis of two spider species with different behaviour, i.e. orb-weaver Nephila clavipes and wandering Cupiennius salei. Their results show that even in the earliest stages (remaining in the cocoon), this body could be easily distinguished. Our results coincide with the above observation: we found the $\mathrm{AB}$ in both larvae and nymphs I of E. atrica. This leads to the conclusion that it is present in spiders regardless of their developmental stage and lifestyle. This contradicts the observation of Babu (1975) that 
the $\mathrm{AB}$ was not yet differentiated in the earliest stages of $A$. aurantia and was fully formed only when spiders started weaving webs. According to Babu (1975), this neuropil mass is correlated with this particular activity. Even if this is true for this species, it does not seem to be a general rule for all spider taxa.

In our study, the proportion of the $\mathrm{AB}$ in the CNS of E. atrica and its neuropil volume decreased gradually, whereas it developed faster than the brain itself, confirming its vital role in the spider biology. Comparative analysis indicates that the $\mathrm{AB}$ in E. atrica develops differently than in other studied species (Weltzien and Barth 1991). In the orb-weaver $N$. clavipes, the earliest stages had a relatively large $\mathrm{AB}$ compared to the brain (over $9 \%$ share). However, this proportion decreased in subsequent stages, before they started to build webs, to be the lowest in adult specimens (3.97\%). In the wandering C. salei, the proportion of the $\mathrm{AB}$ in the brain volume was similar through the entire postembryogenesis: $4.70 \%$ in the earliest stages and $4.80 \%$ in adults (Fig. 4). Our results show that the model of growth of the $\mathrm{AB}$ in E. atrica is different than in the orb-weaver spider and wandering spider. Eventually, the final proportion of the $\mathrm{AB}$ in the brain volume in nymphs $\mathrm{X}$ of $E$. atrica was similar to that of the adult stage of the jumping spider Phidippus regius (3.1\%) (Weltzien and Barth 1991). However, the data on the earlier stages of this species are not known.

In general, it seems justified to state that in spiders, the $\mathrm{AB}$ occupies a relatively small part of the brain, in adults never exceeding several per cent of its volume. Therefore, the results presented by Satija et al. (1970a) suggesting $35 \%$ proportion of the arcuate body in the brain volume of
Oecobius putus and Filistata poonaensis seem questionable. Research on other spider taxa is needed to clarify this issue.

The development of the body and its organs can be associated with their functional role in animal behaviour. This also applies to the central nervous system and its structures in spiders. Their AB was analysed in the context of web building (mainly orb webs) (Hanström 1926, 1928 quoted after Weltzien and Barth 1991; Babu 1975). If the AB was indeed the centre of web-weaving behaviour, web-weaving spiders, such as $N$. clavipes, should boast the largest AB (their web construction requires precision, motor skills and coordination). On the other hand, this structure would be smaller in wandering and jumping spiders. The results, however, contradict this hypothesis. Nevertheless, the influence of the $\mathrm{AB}$ on silk spinning cannot be completely denied, especially since silk can also be used for nest and cocoon construction. Eratigena atrica occupies an intermediate position between the behaviour types shown by the above-mentioned species: it builds webs, though not as complex as typical orb weavers, as well as wanders actively in search of food. Therefore, on the basis of our results and the above-mentioned literature data, it is not possible to associate the dimensions of the $\mathrm{AB}$ with one particular activity. Instead, it is likely that it is involved in several behaviour types, perhaps to various extents in various species. Perhaps this is why its proportion in the total brain volume increases with age in E. atrica, the species exhibiting both high movement and web-weaving activity. In jumping spiders, strongly depending on their vision, the $\mathrm{AB}$ may play yet another role, being an optical centre (Babu and Barth 1984; Babu 1985; Foelix 1996). This suggests a visual function of this body.
Fig. 4 Models of development of the arcuate body in postembryogenesis (expressed as changes in the proportion of the $\mathrm{AB}$ volume in total brain volume) in three species of spiders differing in behaviour: $N$. clavipes, $C$. salei (based on Weltzien and Barth 1991) and E. atrica (our study)

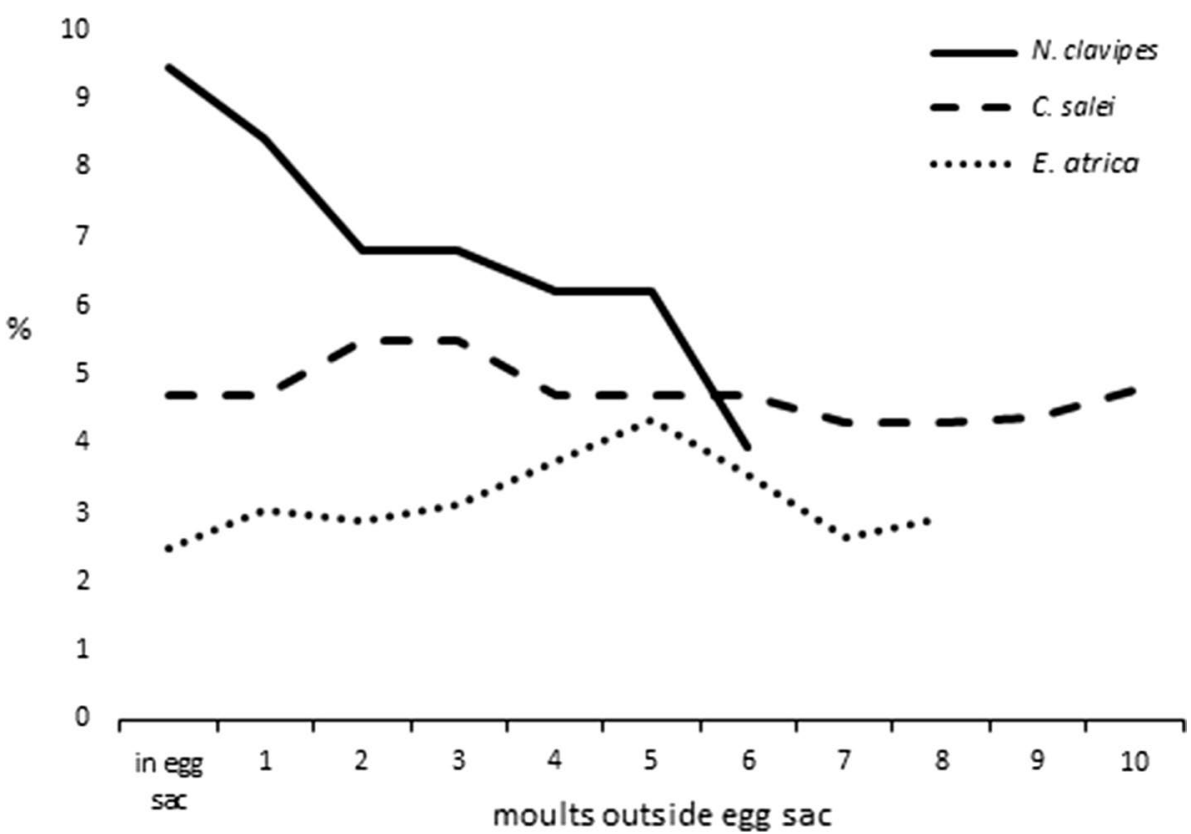


$\mathrm{AB}$

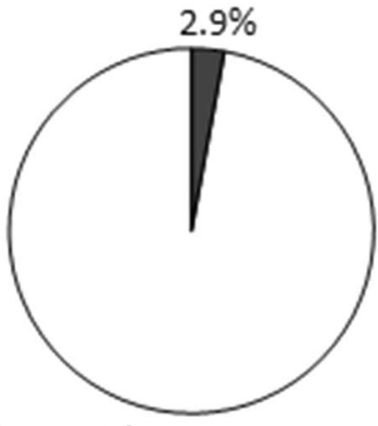

Eratigena atrica

funnel -web spider, weaves a funnel web used for hunting and shelter, sit-and-wait and active hunter

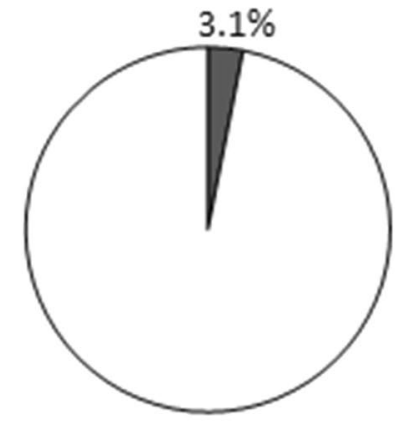

Phidippus regius jumping spider, no webweaving except for cocoons, only active hunter

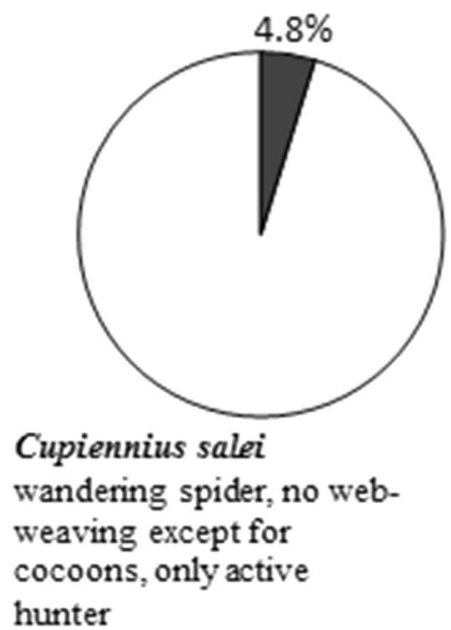

Nephila clavipes orb-web spider, weaves a spiral wheel-shaped web used for hunting and shelter, only sit-and-wait hunter

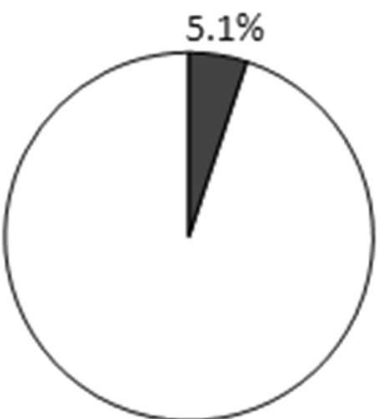

\section{Ephebopus sp.}

fossorial trapdoor spider, uses sill threads to line the burrow and signal the prey presence nearby the shelter, sit-and -wait hunter, but males can wander in search for females

Fig. 5 Volume of the arcuate body of the spider brain given as the percentage of the total brain volume (100\%) in five spider species differing in behaviour: N. clavipes, C. salei, P. regius, Ephebopus sp. (based on Weltzien and Barth 1991) and E. atrica (our study). AB arcuate body

In conclusion, our allometric study of the $\mathrm{AB}$ in Eratigena atrica provides new information on the development of this neuropil mass in the postembryogenesis of spiders. Taking into account previous and present research, we conclude that there is no universal model of how this body develops in these arachnids. However, in adult spiders, regardless of their biology and behaviour, the proportion of the $A B$ in the brain is similar and constitutes several per cent of its volume (Fig. 5).

Acknowledgements This work was supported by the Faculty of Biology and Environmental Protection of the Nicolaus Copernicus University (statutory fund research).

\section{Compliance with ethical standards}

Conflict of interest The authors declare that they have no conflict of interest.

Open Access This article is distributed under the terms of the Creative Commons Attribution 4.0 International License (http://creativeco mmons.org/licenses/by/4.0/), which permits unrestricted use, distribution, and reproduction in any medium, provided you give appropriate credit to the original author(s) and the source, provide a link to the Creative Commons license, and indicate if changes were made. 


\section{References}

Babu KS (1965) Anatomy of the central nervous system of arachnids. Zoologische Jahrbücher. Abteilung für Anatomie und Ontogenie der Tiere 82:1-154

Babu KS (1969) Certain histological and anatomical features of the central nervous system of a large Indian spider, Poecilotheria. Am Zool 9:113-119

Babu KS (1975) Post embryonic development of the central nervous system of the spider Argiope aurantia (Lucas). J Morphol 146:325-342

Babu KS (1985) Pattern of arrangement and connectivity in the central nervous system of arachnids. In: Barth FG (ed) Neurobiology of arachnids. Springer, Berlin, pp 3-19

Babu KS, Barth FG (1984) Neuroanatomy of the central nervous system of the wandering spider, Cupiennius salei (Arachnida, Araneida). Zoomorphology 104:344-359

Barth FG (2002) A spider's world. Senses and behavior. Springer, Berlin

Doeffinger C, Hartenstein V, Stollewerk A (2010) Compartmentalization of the precheliceral neuroectoderm in the spider Cupiennius salei: development of the arcuate body, optic ganglia, and muschroom body. J Comp Neurol 518:2612-2632

Downes MF (1987) A proposal for standardization of the terms used to describe the early development of spiders, based on a study of Theridion rufipes Lucas (Araneae: Theridiidae). Bull Br Arachnol Soc 7:187-193

Foelix RC (1996) Biology of spiders, 2nd edn. Oxford University Press, New York

Hanesch U, Fischbach K-F, Heisenberg M (1989) Neuronal architecture of the central complex in Drosophila melanogaster. Cell Tissue Res 257:343-366

Hanström B (1926) Untersuchungen über die relative Größe der Gehirnzentren verschiedener Arthropoden unter Berücksichtigung der Lebensweise. Zeitschrift Fur Mikroskopisch Anatomische Forchung 7:135-190

Hanström B (1928) Vergleichende Anatomie des Nervensystems der wirbellosen Tiere. Springer, Berlin

Harzsch S, Wildt M, Batelle B, Waloszek D (2005) Immunohistochemical localization of neurotransmitters in the nervous system of larval Limulus polyphemus (Chelicerata, Xiphosura): evidence for a conserved protocerebral architecture in Euarthropoda. Arthropod Struct Dev 34:327-342

Heinze S, Homberg U (2007) Maplike representation of celestial $E$-vector orientations in the brain of an insect. Science 315:995-997

Hoffmann K, Wirner A, Kunst M, Gocht D, Heinrich R (2007) Muscarinic excitation in grasshopper song control circuits in limited by acetylcholineesterase activity. Zool Sci 24:1028-1035

Homberg U (1987) Structure and functions of the central complex in insects. In: Gupta AP (ed) Arthropod brain: its evolution, development, structure, and functions. Wiley, New York, pp 347-367

Homberg U (2008) Evolution of the central complex in the arthropod brain with respect to the visual system. Arthropod Struct Dev 37:347-362

Hwang H-J, Moon M-J (2003) Fine structural analysis of the central nervous system in the spider, Achaearanea tepidariorum (Theridiidae: Araneae). Kor J Entomol 33:119-126

Ioffe ID (1963) Structure of the brain of Dermacentor pictus Herm. (Chelicerata, Acarina). Zool Zhurnal 42:1472-1484

Jacuński L, Wiśniewski H (1997) The influence of the temperature on the duration of embryonic stages of Tegenaria atrica C.L. Koch (Agelenidae). Sci Pap Pedagog Univ Bydg Nat Stud 13:181-203

Jacuński L, Wiśniewski H, Jacuńska K (1994) Effect of temperature on procreation effectiveness of Tegenaria atrica C.L. Koch (Araneida, Agelenidae). Sci Pap Pedagog Univ Bydg Nat Stud 11:77-94
Kovoor J, Muñoz-Cuevas A, Ortega-Escobar J (2005) The visual system of Lycosa tarentula (Araneae, Lycosidae): microscopic anatomy of the protocerebral optic centres. Ital J Zool 72:205-216

Loesel R, Nässel DR, Strausfeld NJ (2002) Common design in a unique midline neuropil in the brains of arthropods. Arthropod Struct Dev 31:77-91

Loesel R, Seyfarth E-A, Bräuning P, Agricola H-J (2011) Neuroarchitecture of the arcuate body in the brain of the spider Cupiennius salei (Araneae, Chelicerata) revealed by allatostatin-, proctolin-, and CCAP-immunocytochemistry and its evolutionary implications. Arthropod Struct Dev 40:210-220

McArdle BH (1987) The structural relationship: regression in biology. Can J Zool 66:2329-2339

Park Y-K, Moon M-J (2013) Microstructural organization of the central nervous system in the orb-web spider Araneus ventricosus (Araneae: Araneidae). Appl Microsc 43:65-74

Park Y-K, Kim H-J, Kim H, Moon M-J (2013) Fine structure of the CNS ganglia in the geometric spider Nephila clavata (Araneae: Nephilidae). Entomol Res 43:330-343

Satija RC, Sharma SP, Dhir RM (1969) Brain of the web spiders, Crossopriza lyoni Blackwall and Cyrtophora citricola Forskal (Arachnida-Araneida, Ecribellata). Zool Pol 19:545-558

Satija RC, Sharma SP, Grewal HK (1970a) Brain and optic centres of the cribellate wall spiders, Oecobius putus Cambr. and Filistata poonaensis Tikader. Zool Pol 20:159-170

Satija RC, Sharma SP, Grewal HK (1970b) Brain and optic lobes in a cribellate spider, Stegodyphus pacificus Pockock (Arachnida-Araneida). Zool Pol 20:87-101

Satija RC, Sharma SP, Dhir RM (1980) Brain and optic centres of the ecribellate spider, Scytodes thoracica (Arachnida-Araneida). Zool Pol 27:469-481

Strausfeld NJ (1998) Crustacean-insect relationships: the use of brain characters to derive phylogeny amongst segmented invertebrates. Brain Behav Evol 52:186-206

Strausfeld NJ (1999) A brain region in insect that supervises walking. In: Binder MD (ed) Progress in Brain Research. Elsevier, Amsterdam, pp 257-284

Strausfeld NJ, Weltzien P, Barth FG (1993) Two visual systems in one brain: neuropils serving the principal eyes of the spider Cupiennius salei. J Comp Neurol 328:63-75

Strausfeld NJ, Strausfeld CM, Stowe S, Rowell D, Loesel R (2006) The organization and evolutionary implications of neuropils and their neurons in the brain of the onychophoran Euperipathoides rowelli. Arthropod Struct Dev 35:169-196

Strauss R (2002) The central complex and the genetic dissection of locomotor behaviour. Curr Opin Neurobiol 12:633-638

Utting M, Agricola H-J, Sandeman R, Sandeman D (2000) Central complex in the brain of crayfish and its possible homology with that of insects. J Comp Neurol 416:245-261

Wegerhoff R, Beridbach O (1995) Comparative aspects of the chelicerate nervous systems. In: Breidbach O, Kutsch W (eds) The nervous systems of invertebrates: an evolutionary and comparative approach. Birkhäuser Verlag, Basel, pp 160-179

Weltzien P, Barth FG (1991) Volumetric measurements do not demonstrate that the spider brain "Central body" has a special role in web building. J Morphol 208:91-98

Witt PN (1969) Behavioral consequences of laser lesions in the central nervous system of Araneus diadematus $\mathrm{Cl}$. Am Zool 9:121-131

Wolff C, Hilbrant M (2011) The embryonic development of the Central American wandering spider Cupiennius salei. Frontiers in Zoology 8:15

Wu C-L, Xia S, Fu T-F, Wang H, Chen Y-H, Leong D, Chiang A-S, Tully T (2007) Specific requirement of NMDA receptors for longterm memory consolidation in Drosophila elipsoid body. Nat Neurosci 10:1578-1586 